\title{
Lipemia retinalis in a 35-day-old infant with hyperlipoproteinemia: case report
}

\author{
Lipemia retinalis em recém-nascido com 35 dias: relato de caso
}

\author{
Marcela Cypel ${ }^{1}$ \\ Roberta Manzano ${ }^{2}$ \\ Frederico Augusto dos Reis ${ }^{3}$ \\ Noemi Ishida ${ }^{4}$ \\ Teruo Ayhara ${ }^{5}$
}

\begin{tabular}{l} 
ABSTRACT \\
\hline A rare case of hyperlipropoteinemia in a 35-day-old infant who presented \\
not only high blood levels of cholesterol and triglycerides but also an \\
ocular manifestation described as lipemia retinalis. The fundoscopic \\
abnormality cleared as the levels of chilomicrons in plasma dropped. \\
Lipemia retinalis is an important and reliable parameter of high levels of \\
chilomicrons and triglycerides and should be considered as a significant \\
clue while diagnosing.
\end{tabular}

Keywords: Hyperlipropoteinemia type I/complications; Hyperlipidemias/complications; Eye manifestations; Retinal diseases; Retinal vessels; Human; Infant, newborn; Case reports [Publication type]

\section{INTRODUCTION}

Heyl was the first to describe lipemia retinalis in $1880^{(1)}$. This rare condition can appear with some types of hyperlipidemia ${ }^{(2)}$. It consist of a creamy white aspect of the retinal vessels on fundoscopic examination ${ }^{(3)}$.

The variation of the aspect in the fundus has been graded: grade I (early) - white and creamy aspect of the peripheral retina vessels; grade II (moderate) - the creamy color of the vessels extends towards the optic disc; grade III (marked) - the retina appears with a salmon color and all vessels arteries and veins present a milky aspect ${ }^{(2,4)}$. The aspect of grade III has rarely been described ${ }^{(2)}$.

Hyperlipoproteinemia is classified into five types, all with high plasma levels of lipoproteins and triglycerides. Type I: hyperchylomicronemia and hypertriglyceridemia and confirmed by lipoprotein lipase deficiency; Type II: major elevation of the LDL (low density lipoprotein), VLDL (very low density lipoprotein), cholesterol and triglyceride; Type III: high levels of LDL, VLDL, cholesterol and triglyceride; Type IV: elevation of VLDL and triglyceride; Type V: elevated levels of VDLD, chilomicrons, cholesterol and triglycerides ${ }^{(3,5)}$.

The ocular features are: xanthelasma, iris and retinal xanthomas, lipid keratopathy and lipemia retinalis ${ }^{(5)}$.

We decided to describe this case because especially lipemia retinalis grade III is rare especially in a child with only 35 days of life.

\section{CASE REPORT}

A female baby with only 35 days of life was admitted to the Emergency Service of the Santa Casa de Misericórdia of São Paulo because of 15-day enterorrhagia. First daughter of a consanguineous marriage (first cousins), 
abdominal delivery, full-term uneventful pregnancy, birth weight $3070 \mathrm{~g}, 47 \mathrm{~cm}$ length; breastfed only. Grandmother with dyslipidemia; first cousin, 7 years, obese, with hypercholesterolemia.

On examination, the child presented a good general aspect, pale $2+/ 4$, hydrated, no fever, eupneic, liver at $3 \mathrm{~cm}$ of the right costal rib and spleen at $1.5 \mathrm{~cm}$ of the left costal rib. Laboratory investigation revealed lipemic serum $4+/ 4$, and it was impossible to determinate hemoglobin, prothrombin and thromboplastin time. Total cholesterol was $1000 \mathrm{mg} / \mathrm{dL}$ and triglycerides were $3000 \mathrm{mg} / \mathrm{dL}$. The baby developed with moderate worsening of general aspect, pale and still with enterorrhagia. Xanthomas appeared in the face and breast. Colonoscopy presented ulcerated lesions in the colon. Two days after admission she underwent blood transfusion. At this moment skimmed milk was introduced and breastfeeding stopped. Subsequent ophthalmologic evaluation was performed (3 days after admission), pupils were isochoric, corneas were transparent, normal ocular tension and ophthalmoscopically a typical fundal picture of lipemia retinalis was noticed in both eyes, all vessels had a creamy aspect and it was difficult to differentiate retinal arterioles from veins (Figure 1).

After seven days of the new diet enterorrhagia stopped the laboratory examinations showed cholesterol over $300 \mathrm{mg} / \mathrm{dL}$ and triglyceride $1178 \mathrm{mg} / \mathrm{dL}$. Twenty days afterwards, cholesterol was $199 \mathrm{mg} / \mathrm{dL}$ and triglyceride $546 \mathrm{mg} / \mathrm{dL}$ and the fundus aspect changed to normal again, the xanthoma disappearing thereafter.

The baby's parents were submitted to laboratory examinations and presented the following: mother - total cholesterol - $197 \mathrm{mg} / \mathrm{dL}$ and triglyceride - $508 \mathrm{mg} / \mathrm{dL}$ and father: cholesterol - $214 \mathrm{mg} / \mathrm{dL}$ and triglyceride - $293 \mathrm{mg} / \mathrm{dL}$.

\section{DISCUSSION}

Lipemia retinalis is an asymptomatic condition that can appear when high levels of triglycerides are present in the circulatory system ${ }^{(5)}$. The retina's white milky aspect occurs when the plasma levels are near to 2000 to $2500 \mathrm{mg} / \mathrm{dL}$ or more ${ }^{(1-2)}$.

It is believed ${ }^{(5)}$ that the changes in the fundus happen in consequence of the elevated levels of circulating chilomicrons at the retinal vessels, but some authors also ${ }^{(6)}$ defend that only the high levels are not sufficient to cause the lipemic creamy serum. The same idea is defended by other authors ${ }^{(7)}$ who justified that we have some cases with elevated levels of chilomicrons and triglycerides that did not present lipemia retinalis suggesting that changes in hematocrit and in the translucence of the retinal and choroid vessels showld be considered.

After intestinal absorption the triglycerides enter the circulatory system and the chilomicrons are the way triglycerides are transported. The chilomicrons are the largest lipoprotein macromolecules, 100 to $1000 \mathrm{~nm}$; VLDL are normally smaller, but some can reach $100 \mathrm{~nm}$. This smaller lipoprotein

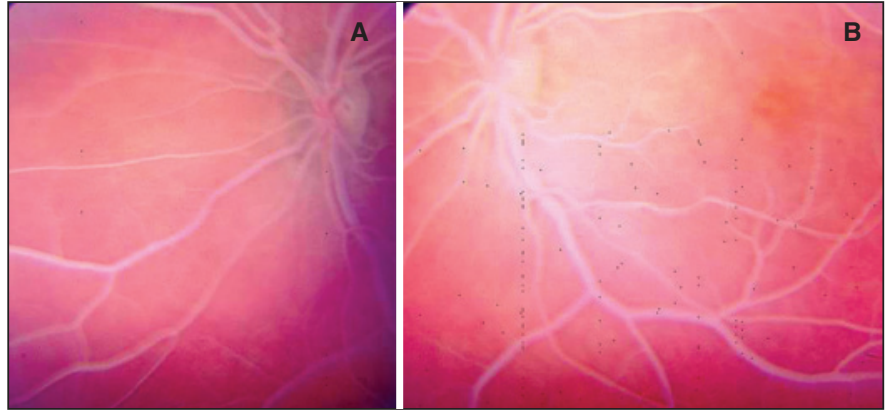

Figure 1 - A right eye and B left eye both with lipemia retinalis grade III: all vessels with a creamy appearance, difficult making it to differentiate retinal arterioles from veins

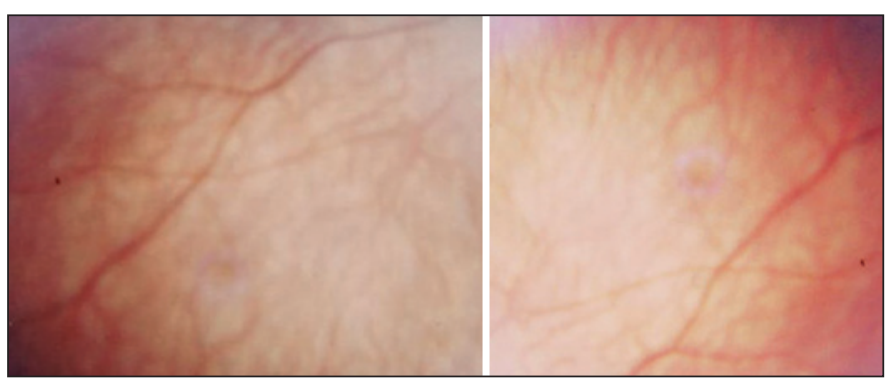

Figure 2 - Peripheral retina vessels recovered normal aspect after treatment

is important for transportation of fat in the metabolism but does not contribute to the change of serum colour ${ }^{(6)}$.

The blood with high levels of chilomicrons can cause the lipemia retinalis fundus at the retina and choroid vessels ${ }^{(2)}$. Some authors ${ }^{(5)}$ believe that the fact responsible for this effect is the dispersion of the light caused by the chilomicrons.

A bibliographic research shows only two cases of lipemia retinalis similar to this one in newborns: a baby with 29 days ${ }^{(2)}$ and a premature one with 77 days $^{(4)}$ that presented lipemia retinalis and retinopathy of prematurity. Both cases had the same evolution as the one described in this paper: once the hyperlipidemia has been detected and the fat in the diet has been restricted, in our case by the substitution of the breastfed for artificial skimmed milk, the clinical findings became normal.

To our knowledge there are no more than 60 publications about lipemia retinalis in the world, and in a Brazil no child with hyperlipoproteinemia associated with lipemia retinalis has been found. The deficiency of lipoprotein lipase is rare in hyperlipoproteinemia, and is characterized by the high levels of chilomicrons in serum. It is an autosomal recessive disease with an incidence of less than 1:1.000.000. Lipoprotein lipase is present in the vascular endothelium and breaks the chilomicrons into glycerol and free fatty acids; the deficiency of lipoprotein lipase causes the accumulation of chilomicrons ${ }^{(3)}$.

The predetermined treatments for these cases are restriction of fat in the diet (less than $10 \mathrm{~g} /$ day) and elevated intake of protein and carbohydrate. Medium chain triglycerides can 
help because their hydrolysis is not dependent on lipoprotein lipase. The ingestion of fat soluble vitamin supplements is also necessary ${ }^{(3)}$.

In 1996, an article presented seven cases of hyperlipidemia but all of them in adults ${ }^{(5)}$. We agree with those who emphasize that lipemia retinalis is an important and reliable parameter of high levels of chilomicrons and triglycerides and should be considered a significant clue while diagnosing ${ }^{(5)}$.

\section{RESUMO}

Caso raro de hiperlipoproteinemia em recém-nascido com 35 dias de idade. Identificados altos níveis de colesterol e triglicérides associados a manifestãção ocular descrita como lipemia retinalis. As alterações oculares mostraram melhora uma vez que os níveis séricos foram controlados. Lipemia retinalis é parâmetro confiável e importante a ser considerado como suspeita de alterações de colesterol e triglicérides em crianças e em adultos.
Descritores: Hiperlipoproteinemia tipo I/complicações; Hiperlipidemias/complicações; Manisfestações oculares; Doenças retinianas; Vasos retinianos; Humanos; Recém-nascido; Relatos de casos [Tipo de publicação]

\section{REFERENCES}

1. Hayasaka S, Fukuyo T, Kitaoka M, Susuki H, Omura K, Kondo Y, et al. Lipemia retinalis in a 29 day old infant with type 1 hyperlipoproteinemia. $\mathrm{Br}$ J Ophthalmol. 1985;69(4):280-2.

2. Rayner S, Lee N, Leslie D, Tompson G. Lipemia retinalis: a question of chylomicrons? Eye. 1996;10(pt 5):603-8.

3. Rotchford A, Newman DK, Moore AT, Flanagan DW, Miles R. Lipemia retinalis in a premature infant with type I hyperlipoproteinemia. Eye. 1997; 11(Pt 6):940-1.

4. Shankar KN, Brava HS, Shetty J, Joshi MK. Lipoprotein lipase deficiency. J Postgrad Med. 1997;43(3):81-2.

5. Vinger PF, Sachs BA. Ocular manifestations of hyperlipoproteinemia. Am J Ophthalmol. 1970;70(4):563-72.

6. Winder AF. Disorders of lipid and lipoprotein metabolism. In: Garner A, Klintworth GK, editors. Pathobiology of ocular disease: a dynamic approach. New York: Dekker; 1982. p.1047-75. 